\title{
Biochemical Profile Affects IoPTH Kinetics and Cure Rate in Primary Hyperparathyroidism
}

\author{
F. Fausto Palazzo ${ }^{1}$
}

Published online: 11 October 2019

(C) The Author(s) 2019

The decades since the arrival of the serum autoanalyser in the 1970s have been accompanied by sequential changes in the clinical complexion and treatment of primary hyperparathyroidism (pHPT). There was initially a sequential move from treating patients with symptomatic renal calculi, osteoporosis and pancreatitis to the treatment of pHPT without symptoms but with radiologically detected end organ damage. The iterations of the International Consensus Guidelines on the treatment of asymptomatic disease drew a line in the sand by advocating surgery for patients that met specific criteria that predict adverse outcomes such as age and biochemistry [1]. More recently, parathyroidectomy has become regularly adopted for patients without the international consensus criteria but with subjective neurocognitive symptoms. The latest lowering of the surgical threshold in pHPT consists in the treatment of normocalcaemic (NC) HPT.

The evolution in the nature of pHPT has allowed the separation of the disease into three entities of pHPT: classic pHPT, normohormonal (NH) HPT and NC pHPT as described in this paper by Graves et al [2]. A single-institution 8-year retrospective review of just under 650 parathyroidectomies has permitted the assessment of the kinetic of intraoperative PTH (IoPTH) in the three types of pHPT. The conclusion clears that IoPTH kinetic appears to be most predictable in classic HPT and most contributory in the context of targeted surgery. Targeted surgery, however, is only an option in localised disease which is less common in both NC HPT and NH HPT. It seems that the more subtle the nature of pHPT the greater the role of

\footnotetext{
F. Fausto Palazzo

f.palazzo@imperial.ac.uk

1 Hammersmith Hospital, Imperial College London, London, UK
}

surgical judgment and less the influence of medical technology.

The data presented support the view that NH HPT represents an earlier phase of classic pHPT. Indeed, NH HPT has similar rates of single-gland disease and cure rates to classic pHPT and substantiates the existing literature that demonstrates lower gland weight in NH HPT [3].

In contrast, NC HPT is more frequently scan negative, more commonly associated with multiple gland disease (or at least multiple gland removal) and has a high failure to cure rate even in specialist centres. Unlike in the USA, NC HPT represents a very small part of parathyroid practice in the UK's publicly funded healthcare system. Given the high failure to cure rate and the permanent hypoparathyroidism rates that may occur following multiple parathyroid gland removal, the threshold for surgery in asymptomatic NC HPT patients may require review unless cure and hypoparathyroidism rates similar to classic pHPT can be achieved.

Open Access This article is distributed under the terms of the Creative Commons Attribution 4.0 International License (http://crea tivecommons.org/licenses/by/4.0/), which permits unrestricted use, distribution, and reproduction in any medium, provided you give appropriate credit to the original author(s) and the source, provide a link to the Creative Commons license, and indicate if changes were made.

\section{References}

1. Bilezikian JP, Brandi ML, Eastell R et al (2014) Guidelines for the management of asymptomatic primary hyperparathyroidism: summary statement from the Fourth International Workshop. J Clin Endocrinol Metab 99(10):3561-3569

2. Graves CE, McManus CM, Chabot JA et al (2019) Biochemical profile affects IOPTH kinetics and cure rate in primary 
hyperparathyroidism. World J Surg. https://doi.org/10.1007/ s00268-019-05157-x

3. Almquist M, Bergenfelz A, Mårtensson H et al (2010) Changing biochemical presentation of primary hyperparathyroidism. Langenbecks Arch Surg 395(7):925-928
Publisher's Note Springer Nature remains neutral with regard to jurisdictional claims in published maps and institutional affiliations. 